\title{
Reflections on the Dasgupta Review on the Economics of Biodiversity
}

\author{
Ben Groom ${ }^{1}$ (D) $\cdot$ Zachary Turk $^{2}$
}

Accepted: 7 April 2021 / Published online: 21 April 2021

(C) The Author(s) 2021

\begin{abstract}
The Dasgupta Review provides a rich overview of the economics of biodiversity, paints a bleak picture of the current state of biodiversity, and is a call to arms for action in anticipation of the CBD COP 15. The Review takes a global perspective aimed at the high level of international and national policy on biodiversity, while elucidating the very local nature of biodiversity threats and values. The approach is orthodox in its diagnosis via the language of externalities, natural capital, shadow pricing, asset returns, and the suite of remedial policies that follow. Yet, at its centre is an 'unorthodox' perspective: the economy is embedded in the environment and growth is limited. We offer reflections on this framing in light of its objectives for biodiversity. The limits to growth message will be criticised and applauded in equal measure by different economists. The central place of valuation and the aggregated concept of biodiversity will draw criticism from outside the discipline. Yet the Review provides a foundation for biodiversity economics, and its largely orthodox framing may invoke the intended step change in the mainstream approach to economic growth.
\end{abstract}

Keywords Biodiversity $\cdot$ Dasgupta Review $\cdot$ Economic growth $\cdot$ Natural capital $\cdot$ Limits to growth

\section{Introduction}

The Dasgupta Review on the Economics of Biodiversity is a comprehensive and high-level report on the economic explanation behind the current state of global biodiversity, the failings of the economic system that are responsible. It provides the policy prescriptions that economists ought to be making to reverse the impending, some would say current, disaster

This paper has benefited from comments from Ben Fine, Daan van Soest, Frank Venmans, Ian Bateman, Sanchayan Banerjee, Glen Gostlow and Ben Balmford. The usual disclaimer applies.

Ben Groom

b.d.groom@exeter.ac.uk

1 Dragon Capital Chair of Biodiversity Economics, Department of Economics, LEEP Institute, University of Exeter Business School, Exeter, UK

2 Department of Geography and Environment, London School of Economics and Political Science, London, UK 
that the unfettered global economy is having on the biosphere (Bradshaw et al. 2021). The statistics are eyewatering. Over the past 11000 years, the start of agriculture, terrestrial vegetation biomass has halved. Moreover, in the last 500 years alone more than $20 \%$ of biodiversity has been lost, including over 700 plants and around 600 vertebrate species becoming extinct (Bradshaw et al. 2021). The current rate of extinction is 15 times the background rate, meaning that we are on course for a mass extinction event (75\% loss of species in a 'geologically short period': < 3m years, (Ceballos et al. 2015)). Populations are down too, by nearly $70 \%$. Furthermore, although known for some time that biodiversity loss, habitat destruction and the trade in wild animals is linked to zoonoses (e.g. Daily and Ehrlich, 1996; Pepin, 2013), we now find ourselves in the middle of a global pandemic that appears to be linked to the sale of exotic species and the destruction of their habitats (Wu et al., 2020). The costs of environmental degradation are now very tangible.

The Review, housed at the UK Treasury, is "high-level" in that its fundamental aim was not to preach to the choir of environmental economists, but to ministries at the core of governments worldwide, that make decisions on economic policy, the measurement of long-term well-being and the economic incentives that affect biodiversity and nature. It is aimed at finance ministries, central banks and, particularly, the mainstream economists that work in and advise these institutions, which in turn determine the allocation of public and private capital. ${ }^{1}$ In the Q\&A of the Review's launch event, the first question that Sir Professor Dasgupta was asked, was "what is the first thing that you would change?". His response was telling: "my colleagues in the economics profession". This response encapsulates the view that mainstream economic theory of growth has been hegemonic, influential and stubbornly persistent as the theoretical platform for defining economic goals worldwide. If one discards the decades of work in environmental economics at least since Dasgupta and Heal (1974) and Dasgupta and Heal (1980) from the category of 'mainstream' growth economics, mainstream theories of economic growth have essentially ignored the demands economic activity places on the biosphere and the constraints that the biosphere places on economic activity. ${ }^{2}$ The Dasgupta Review is comprehensive, detailed and thorough on the role of biodiversity in determining well-being from the micro to the macro level. Nevertheless, it is this high level macroeconomic point that is the essential message. The economy is embedded in the environment, and the biosphere and the biodiversity contained within it is not something that can be easily substituted. Neither can technological change solve the essential imbalance between the demands of economic activities, and the renewable output of the environment. There are, the Review argues, limits to growth due to embeddedness in the biosphere and binding planetary boundaries.

Realising this aim and communicating this message requires the right language, one that can be understood at a high level and by the mainstream. The idea that biodiversity is valuable at the macroeconomic level requires the language of natural capital, assets and asset returns, stocks and flows and national accounts, when its audience is the mainstream economists in ministries and in finance. This language, while probably anathema to many who are concerned about biodiversity loss and who see economics as the problem, is also necessary within the theoretical framework that Dasgupta uses: a hybrid of mainstream

\footnotetext{
1 It is actually difficult to define 'mainstream' cleanly these days, but we have in mind the traditional training in the economics of growth which in our experience, and often still, barely touched on the environment but was heavily focused on neoclassical and endogenous growth.

2 In climate change economics, Integrated Assessment Models do not typically constrain growth (Nordhaus 2017).
} 
economic growth theories which presents biodiversity as a macro aggregate stock and flow. From the perspective of environmental and resource economics (ERE), this framing is familiar ground. Less so within the mainstream. Yet, as we discuss, the idea of limits to growth and the embeddedness of economy in biosphere is an important departure both from the mainstream and typical discussions of sustainable economic development in ERE (e.g. Hamilton and Hepburn 2017). Embeddedness is more in the realm of ecological economics (e.g. Boulding 1968). Irrespective of these discussions, limits to growth is one thing, imposing limits on growth to rebalance economic demands with the environment is quite another.

With these high level aims and the audience in mind, in what follows the way in which the Dasgupta Review's message is conveyed is explored, and some of the key ideas are discussed. Of course, the Review is more than these aims and the language of ERE. The attention to detail is impressive given the broad coverage of topics. Among the numerous things that we learn from the Review are the manifold values that biodiversity can provide. The abridged version tells us that $60 \%$ of cancer drugs in the 90 s came from soil funghi and bacteria (See Box 2). We also learn that subsidies to activities that harm biodiversity run to about US\$4-6 trillion annually (Box 8.1 of the Review), and that in a stress test of the Dutch Financial Sector, $€ 1.4$ trillion of investments were highly dependent on ecosystem services, and that the footprint of Dutch Financial institutions' investments is the equivalent of $58000 \mathrm{~km}^{2}$ of pristine natural habitat $(25 \%$ more than the area of the Netherlands itself. See Box 17.8 of the Review). Furthermore, were everyone to consume the diets seen in rich countries today, it would require an area of land greater than the entire surface of the globe. Such is the evidence of overshooting sustainable use of the biosphere.

The Review will be a key resource for economists and policy makers from here on. The aggregated approach to biodiversity, which ostensibly glosses over the complexities of biodiversity and the role it plays in the embedded economy (see Pascual et al. (2021) for a perspective), can be understood in terms of the audience and the high level aims of the Review. While light on specific policies and only hinting at practical steps, the Review provides a much needed foundation upon which debates on limits to growth can be centred, and policy responses subsequently built. The following sections hope to contribute to both.

\section{Measuring Biodiversity}

In order to understand the high-level arguments that the Dasgupta Review makes concerning the role of biodiversity in the economy, and the economy within the biosphere, it is important to understand the way in which biodiversity is conceived of in the Review. The measures of biodiversity and Natural Capital that are used to make the main arguments in the Review are the equivalent of the macroeconomic aggregates of flows like output or income $(Y)$ on the one hand, and the stocks of 'labour' $(L)$ and 'capital' $(K)$ on the other, that appear in typical neoclassical growth models. Net Primary Product (NPP) is the flow of biomass regenerated by a stock of primary producers (plants, algae, bacteria) that are the building blocks for species, ecosystems and communities, which fall under the umbrella term of natural capital. Primary producers convert primary energy sources into useful biomass and other inputs which flow into these higher ecological structures. There is biodiversity both within ecosystems, in the genetic diversity within and between species, 
and between ecosystems, communities and biomes. ${ }^{3}$ Aggregate NPP has the same level of abstraction as the typical macroeconomic flows, containing a wide variety of biomass, and the stocks that produce NPP are also diverse. Just as output is a collection products measured in a common metric, so is NPP. Just as $K$ is an abstraction to many different forms of productive man-made capital, so is the stock of primary producers and ultimately natural capital of which they are part. The need for such stock and flow measures of biodiversity reflects both the theory of sustainable economic development and its focus on wealth as the determinant of long-run well-being, as seen in Arrow et al. (2012), but also the aims and audience of the Review as discussed above. The framing fits the arguments that need to be made and the audience of macroeconomists that are being targetted. NPP is also potentially more easily understood as being relevant to economic growth than some other measures of biodiversity that could have been used, such as species richness, genetic diversity, 'intactness' or even habitat. NPP reflects an emphasis on functionality in the measurement of biodiversity in supporting ecosystems, generating ecosystem services and engendering resilience. Using NPP also allows a fairly standard Natural Resource Management framing for conveying ideas about biodiversity formally.

Conceptually then, NPP has clear practical appeal with regard to the audience, the context of economics growth and the central message of the Review. Fears that this definition of biodiversity is too limited are allayed in $\mathrm{Ch} 2$, which is a useful reference in its own right to help navigate this complex territory. There is a firm ecological basis, rooted in the ecological literature, for framing biodiversity via NPP. Nevertheless, NPP does not necessarily satisfy all of the characteristics that are typically associated with biodiversity. For instance, the correspondence between NPP, the biomass produced each year, and biodiversity is not always positive. There are situations where NPP is large in non-diverse systems, such as mono-crop plantations or agriculture, grassland ecosystems, or some fisheries. ${ }^{4}$ Neither does NPP necessarily reflect the nuances of anthropocentric or intrinsic values of biodiversity. Such values view biodiversity as a direct determinant of welfare (e.g. aesthetic values) or as a store of information that affects or, via solving future problems of pathogen resistence, has the potential to affect welfare indirectly (genetic diversity in itself), or as an aspect of natural capital / wealth with associated ecosystem services (Mace 2014). Yet the Review convincingly positions NPP as the key lens through which to understand the many roles of biodiversity: biodiversity contributes to NPP, it is an outcome of primary production, and it facilitates natural capital and its resilience in a way analogous to the way trust facilitates economic activity. Care is naturally taken to separate out the valuation side from the product/biomass side. For instance, the shadow prices for invasive species are likely to be negative, despite successful biomass production. Some aspects of biodiversity do not have a positive value for humans, and are effectively pollutants (See Section 2.6).

The focus on the functionality of biodiversity, and NPP as the central concept means that some measures of biodiversity are virtually ignored. Fans of Weitzman's work on measuring biodiversity will be disappointed to see no mention of what some would argue are seminal works. From a functionality perspective, such measures, which focus on genetic distinctiveness, typically ignore quantity/population size, the distribution of species on the ground, and complex interactions within ecosystems. While practical examples of Weitzman's measure exist for primates (Jean-Louis et al. 1998), cattle (Reist-Marti

\footnotetext{
3 The first four paragraphs of Ch 2 elegantly summarise these relationships.

4 E.g. a eucalypt plantation in a wetland increases NPP while reducing most ecosystem services, other than perhaps carbon sequestration.
} 
et al. 2003) and cacao (Samuel 2013), and extensions to include more complex ecological relationships have been attempted (van der Heide et al. 2005; Courtois et al. 2014; Simianer and Simianer 2008) such measures are perhaps more appropriate for more specific informational problems, like organising gene banks or specific conservation interventions. ${ }^{5}$ It is difficult to see how such measures could be central to the objectives of the Review. Yet, despite the thorough justification for the framing of biodiversity around NPP in the Review, perhaps one criticism might be that it skirts around some of the more practical aspects of measuring biodiversity, particularly which measures of biodiversity are useful for which purpose. Nevertheless, one thing the Review's conception of biodiversity has in common with Weitzman's informational-type measure is that the focus is taken away from matters relating to particular (e.g. flagship) species that humans find important, more subjective ideas of 'pristine-ness' and normative ideas of what conservation ought to do. Of course, the aggregated and functional NPP approach does not solve all disputes about the meaning and definition of biodiversity that beset pluralistic approaches. Pascual et al. (2021) provide a fascinating excursion into these difficulties.

The special characteristics of biodiversity that require specific attention in economics are discussed at length, often making the point that standard economic analysis is sometimes inappropriate. A good example in Ch 13 concerns the discussion of non-linearities in the environment and biosphere, which essentially invalidate marginal analysis if the objective is to find the best sustainable equilibrium. Chapters 3 and 4 discuss the lumpiness and complementarity of investments in ecosystem services, and how a fragmented approach would not necessarily pass a CBA test if it ignored such complementarities. Furthermore, Weitzman's dismal theorem is used as an example of how conventional CBA may fail in the presence of fat-tailed uncertainty (Weitzman 2009). Just as in climate change policy where there is a serious rift between the Social Cost of Carbon and the carbon price people face, the Review argues the same is an 'important truth' (p. 168) with regard to biodiversity. The next section explains how the Review formalises this point (in general terms) in a model of growth embedded in the environment.

\section{Limits to Growth?}

The Review's central messages is that the economy is embedded in nature, and hence dependent on it. This is short-hand for saying that there are limits within which economic activity should remain. The formal analysis in the supplement to $\mathrm{Ch} 4\left(\mathrm{Ch} 4^{*}\right)$ models embeddedness via a materials balance constraint, which reflects the demands of economic activity on a generic renewable natural capital asset. As discussed in $\mathrm{Ch} 4$, the basis of this framing is closely related to, and motivated by, the concept of planetary boundaries first discussed by Rockstrom et al. (2009) and Steffen et al. (2015), which point out the quantitative constraints on various natural processes and the current demands placed upon them by economic activity (climate, nitrates, forests, biodiversity etc). The materials balance ideas also harken back to Boulding and Georgescu-Roegen, whose steady state economy ideas remain influential, if nowhere else than in ecological economics (Boulding 1968; Georgescu-Roegen 1971).

\footnotetext{
5 Such measures can capture values of biodiversity in managing risk and well-being that biomass may not (Brock and Xepapadeas 2003), and Box 2.1 of the Review acknowledges the role of genetic diversity.
} 
The model is recognisable as a more or less standard natural resource modelling approach, applied to the economy as a whole. The limits presented here are not exactly the 'limits to growth' in the sense of the Club of Rome report of the early 70s, which emphasised non-renewable resources and their imminent exhaustion (while forgetting relative price changes and substitution), but rather focus on the renewable flow of NPP, and the erosion of the stocks (the primary producers and other aspects of natural capital) that underpin NPP. The chief concern of the Dasgupta Review is that the demands placed on the biosphere outstrip the renewable supply of NPP from natural capital, from which flow the benefits of biodiversity and nature (fish, soil, water quality, forests, climate, etc.). Ch 4 provides two arguments to suggest that biodiversity has been run down too much, and is in danger of collapse. First, the Review argues that these natural assets are currently below the level that can maximise well-being by looking at the disparity in returns compared to man-made capital: a disparity of 14 percentage points in favour of Nature's primary producers (See box 2.3 and Bar-On et al. (2018)). Second, there is a considerable imbalance or 'impact inequality' since according to Wackernagel et al. (2019b), estimates of the global ecological footprint suggest that the demands on NPP are approximately $170 \%$ of the supply. This erosion of natural capital is unsustainable since these stocks are for the most part irreplaceable in aggregate, and not generally substitutable for physical or other capitals. ${ }^{6}$

It should not be underestimated how much of a departure the idea of embeddedness and planetary boundaries are to the mainstream of economic growth. Neither should it be forgotten that issues of sustainability and its relationship to renewable and non-renewable natural resources are absolutely familiar to environmental and resource economists, since Dasgupta and Heal (1974), Stiglitz (1974), Hartwick (1977), and Dasgupta and Heal (1980), via Hamilton et al. (1999), Arrow et al. (2004), Pezzey (2004) and Dasgupta (2010), until more recent policy pieces like Arrow et al. (2012), collections like Hamilton and Hepburn (2017) and textbook analyses of Fleurbaey and Blanchet (2013). Furthermore, the embeddedness idea is pretty much the essential and definitional departure point for ecological economics. Yet, while the idea of limiting the demands on environmental and natural resources seems intuitive, and is well-trodden ground in the field (environmental and resource, and ecological economics), it is not the focus of mainstream growth economics, which emphasises the role of technical change and institutions in driving perpetual growth (Acemoglu et al. 2001; Romer 1990; Aghion et al. 2004). Even recent proposals for better measures of macro performance have avoided the environment (Jones and Klenow 2016). There are some high profile exceptions that address the environment, such as Nordhaus' work on climate change, Brander, Copeland and Taylor's work on trade and the environment (e.g. Copeland and Taylor 2004), and Acemoglu et al. (2012), but these still remain firmly 'unembedded' in the terminology of the Review. In each case the environment is just tacked-on, seen more as a sink for pollutants than the basis of well-being, and infinite growth is always possible. An exception to this is Brander and Taylor (1998), which focused on the boom-bust environment-population travails of Easter Island but is otherwise intended to be canonical. ${ }^{7}$ With these exceptions, even within environmental and resource economics, when it focuses on sustainability there has been a strong emphasis on the substitutability of natural capital for other forms: weak sustainability (e.g. Hartwick

\footnotetext{
6 The evidence provided makes for quite stark reading. E.g. with current technologies if everyone on the planet had the same diets as those in high income countries, the amount of land required would exceed the surface area of the planet, sea included.

7 Solow has also criticised new growth theories of the 'AK' type (Solow 1994).
} 
1977; Hamilton et al. 1999), with some notable exceptions such as Neumayer (2012). Physical laws and material and balances are more the realm of ecological economics.

As the Review makes clear in Ch 4, recent contributions, such as Arrow et al. (2012), do not make weak sustainability assumptions per se when making the positive connection between comprehensive wealth measures and long-term, sustainable, well-being. Rather, they emphasise the important role of shadow prices to reflect the approaching non-substitutability, tipping points or subsistence constraints. Nevertheless, whether weak or strong, sustainability has largely been the reserve of environmental, resource and ecological economics. Coupled with embeddedness and limits to growth, the Review is a deliberate departure from mainstream growth theory.

Irrespective of its provenance, from the perspective of long-run growth, there are three immediate questions that arise from the Review's framing of biodiversity economics in the aggregate. First, are there really inherent limits to growth as economists understand it? Second, if we are beyond the limits of sustainable demands on NPP, how far, and how pressing is the action required? Third, how can we correct the imbalance? Is a period of degrowth required, or can we rely on technological change? The next section looks at the formal representation of the embedded economy from $\mathrm{Ch} 4^{*}$ of the Review as a means of discussing some of these points.

\subsection{Formal Model of the Embedded Economy}

The formal analysis of the economy embedded in the environment/nature adjusts the Solow framework to include a materials balance equation (See Ch $4 *$ ). Embeddedness appears first in a resource dynamics equation, which is an 'impact inequality' when natural regeneration, $G(S)$, is outweighed by the direct harvesting, $R=\frac{Y}{\alpha_{X}}$, and the indirect demands of the economy as a whole, $\frac{Y}{\alpha_{z}}$ :

$$
\frac{d S}{d t}=G(S)-\frac{Y}{\alpha_{X}}-\frac{Y}{\alpha_{z}}
$$

where $\alpha_{X}>0$ and $\alpha^{*} \geq \alpha_{z}>0$ and $r$ is intrinsic growth of $S$. Also, $G(S)$ is subject to constraints of its own such that $G(S)=r S[1-S / \underline{S}][(S-L) / \underline{S}]$, where $L$ is the minimum viable level of natural capital: above this is the 'safety zone', and $\underline{S}$ is the global carrying capacity. The second and third terms on the RHS reflect first direct extraction of $S: R=\frac{Y}{\alpha_{X}}$, and the indirect resource intensiveness of output (coupling): $\frac{Y}{\alpha_{z}}$. With output $Y$ also dependent on $S$ and the flow of renewable resources, $R, Y=A f(S, K, H, R)$, the embeddedness of the economy in nature is completed by the constraint $\alpha^{*} \geq \alpha_{z}>0$. This conception of the economy contains limits to growth. Exogenous growth in $Y$ via $A$ (TFP) eventually leads to more demands on $S$ via the materials balance equation until an impact inequality occurs and $\frac{d S}{d t}<0$ and eventually $\frac{d Y}{d t}<0$. How quickly this happens depends on how close the economy is to exiting the safe zone defined by L. Figures 1,2 and 3 show the optimal paths of growth and development associated with this model. These optimal paths are not necessarily sustainable, and typically lead to negative growth in the future. Figure 1 shows the sensitivity of the optimal path to the planetary boundary, represented by $L$. If the economy is operating below the safe zone so $S<L$ (which is represented by numbers lower than 1 in Fig. 1) a collapse of GDP and the biosphere happens sooner than if the economy is well within the safe zone. The perception of positive growth over the next few years belies the negative growth that is to come. Still, the time horizons are important, as are changes in the 
other parameters of the model. Figure 2 shows similar results for GDP per capita (GDPpc), in which the downturn due to the impact imbalance is starker with higher population growth. Furthermore, in this set up, technological change also 'buys time', to use Dasgupta's phrase, but technological change cannot separate the economy from the environment. The key to this point is that $\alpha_{Z}$ is bounded above to $\alpha^{*}$, meaning that technological change can never completely decouple the economy from the environment. Figure 2 shows that larger values of $\alpha_{Z}$ merely postpone the inevitable decline of an optimal path.

These dynamics capture the point that there are relevant policy interventions to be had in relation to technological change and population growth, but the long-run implications are inescapable: growth ad infinitum is not possible in an embedded economy. The prognosis looks particularly bad if the analysis of ecological footprints is correct, which suggests that global demands on NPP outstrip global supply by a factor of 1.7 , so $S<L$, compared to 1970 after which the global consumption left the safe-zone (See Box 4.6) (Wackernagel et al. 2019a).

The decline in GDP per capita arises because as the level of GDP rises so do the demands on the biosphere, and optimality trades off growth today, overshoot and degrowth tomorrow. Of course, the paths illustrated are optimal paths in an augmented Solow model. An environmentally sustainable path could in principle be chosen, one that stays within the planetary boundaries, such that $\frac{d S}{d t}=0$. Is positive growth possible forever in this case? The answer is found in the materials balance condition with the limiting constraint on $\alpha_{Z}$. Working this through, consider the materials balance equation and how this changes over time:

$$
\begin{aligned}
& \frac{d}{d t} \frac{d S}{d t}=\frac{d}{d t}\left[G(S)-\frac{Y}{\alpha_{X}}-\frac{Y}{\alpha_{Z}}\right] \\
& \quad=G_{S}(S) \dot{S}-\left[\left(\frac{1}{\alpha_{X}}+\frac{1}{\alpha_{Z}}\right) g_{Y}-\frac{g_{\alpha_{X}}}{\alpha_{X}}-\frac{g_{\alpha_{Z}}}{\alpha_{Z}}\right] Y
\end{aligned}
$$

With $\dot{S}=0$ and with $\alpha_{Z}$ reaching the limit $\alpha^{*}$ in the long-run, for the steady state to remain with positive growth in GDP, the conditions on growth and technological change are:

$$
g_{\alpha_{X}}\left(\frac{\alpha^{*}}{\alpha^{*}+\alpha_{X}}\right)=g_{Y}
$$

which means that for a time technological change in $\alpha_{X}$ can be relied upon to maintain positive growth, but as $\alpha_{X}$ gets larger, the only sustainable level of growth in GDP is 0. Worse, this analysis does not contain any rebound-type effects on demand. The formal connection would be that technological change in extraction (increased $g_{\alpha_{X}}$ ), leads to a higher impact of income on the biosphere (lower $g_{\alpha_{Z}}$ or $\alpha^{*}$ ). The Review provides agricultural intensification as an example of this process, which reduces the demands on land and soils, but raises pesticide and herbicide use. Indeed, there are many such endogenous processes that this stylized model does not reflect.

\subsection{Optimal Growth Paths}

The Review ultimately has a limits to growth message, with the best long-term outcome being a steady state economy. The constraints on decoupling define the point at which optimal growth returns to zero, and the level of GDP at which this occurs. Sustainable growth is only possible over the longer term within this framework if saving remains 
Fig. 1 GDP and Biosphere paths of the embedded economy: The top graph plots GDP per capita for various levels of the 'safespace' or planetary boundary $L$. A value less than 1 means that the current stock $S$ is below the planetary boundary. In all cases, demands on NPP eventually outstrip supply: the 'impact inequality'. The bottom graph plots the associated mining of the biosphere, $S$, with different growth paths according the the level of the planetary boundary, $L$
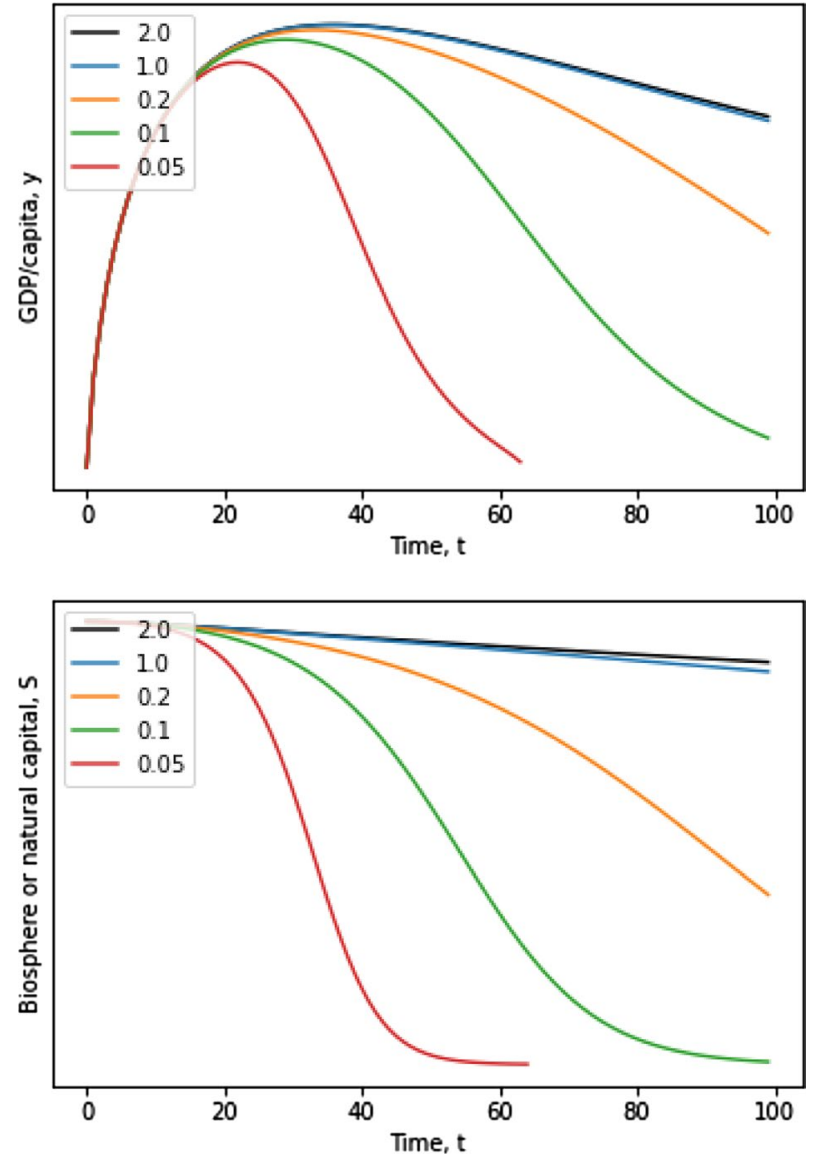

very low and increases slowly. Indeed, high levels of saving increases capital and output, and hence the demands on the biosphere. Figure 3 shows the optimal paths of growth for different savings rates and time horizons, showing that embeddedness brings a very different logic to growth. For instance, higher savings rates, the driver of growth in the neoclassical frame, brings a collapse sooner due to its effect on $Y$ and then $S$ (see the lower panel of Fig. 3).

Of course, it is well understood since Dasgupta and Heal (1980) that the optimal path is problematic when it comes to environmental resources and sustainability, leading to similar collapses in consumption if we discount future utilities. Yet, in the Dagupta-Heal-Solow-Stiglitz (DHSS) model sustainable, Rawlsian constant consumption paths are possible with sufficient substitutability of the non-renewable resource flow for physical capital. Even rising consumption paths are possible in the simpler nonrenewables framework, provided genuine savings are positive and not growing too fast (Hamilton and Clement 1999; Arrow et al. 2012; Hamilton and Hartwick 2014). Yet in the embedded economy, where $S$ and $R$ are essential, such rising paths are not possible because rising incomes eventually imply a path of biosphere exhaustion that cannot be compensated for by increases on human or physical capital. 
Fig. 2 Growths paths of the embedded economy: Optimal GDP paths with different levels of population growth and technological change. In the lower graph, $\alpha^{Z}$ grows logistically to the limit $\alpha^{*}$, with the starting value multiplied by the numbers 0.1 to 10
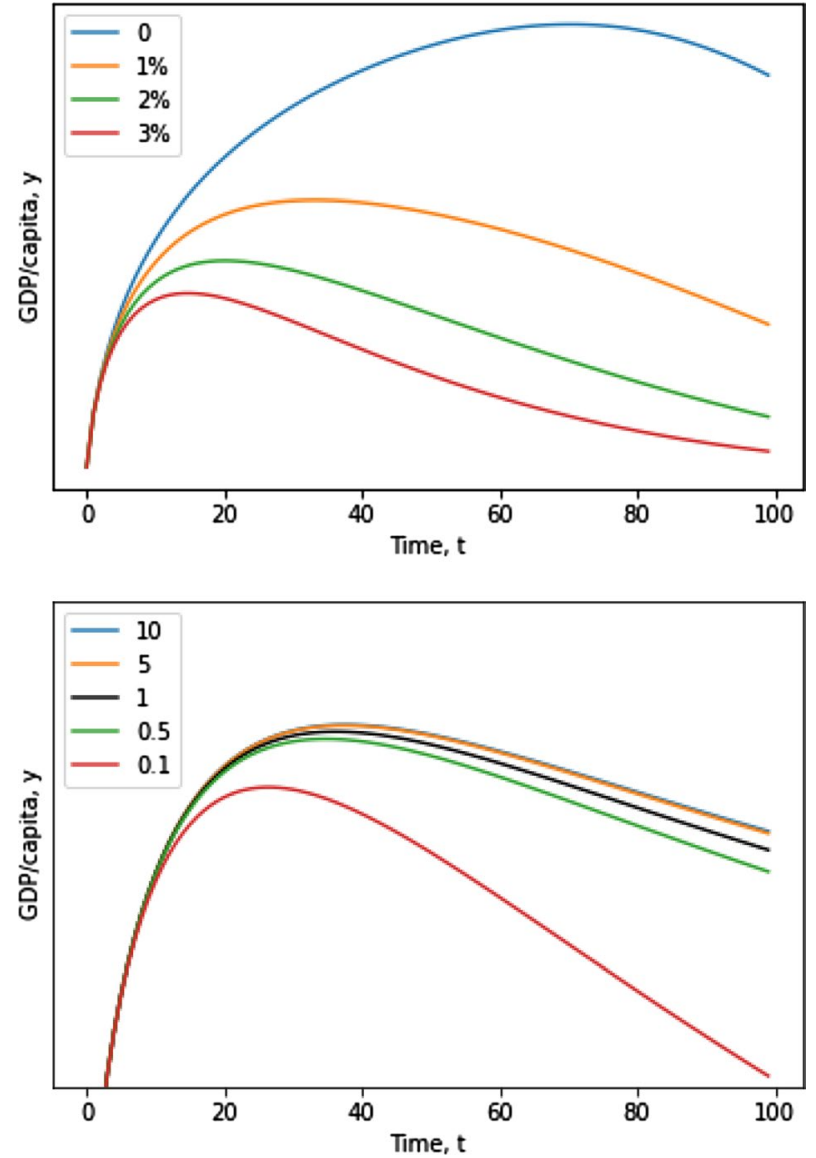

While new to mainstream economists, this message will not be new to ecological economists, and certainly has echoes of past works on steady state growth. As Boulding (1968) writes:

When we have developed the economy of spaceship earth, in which man will persist in equilibrium and his environment, the notion of GDP will disintegrate. We will be less concerned with income-flow concepts and more with capital-stock concepts. Then technological changes that result in the maintenance of the total stock with less throughput (less consumption and production) will be a clear gain.

This is not far from the Review's position, and similarly leaves open the role for technological change to ease the path to a steady state. The limits to growth idea will certainly be debated. Some who focus on planetary boundaries and ecological footprints could well argue that provided those physical boundaries are adhered to, the economy can get on with the business of decoupled growth. Others will seize upon embeddedness as an affirmation that degrowth is necessary. Others will remain agnostic about GDP growth altogether (van den Bergh 2011).

On the question of whether we have yet exceeded the planetary boundaries, and whether there is an impact inequality, the Review ultimately places a great deal of stock 
Fig. 3 Growth paths of the embedded economy: Top: Optimal GDP paths with typical savings rates show an earlier collapse of GDPpc with high savings rates. Bottom: long-term growth sustained at a low level with low savings rates
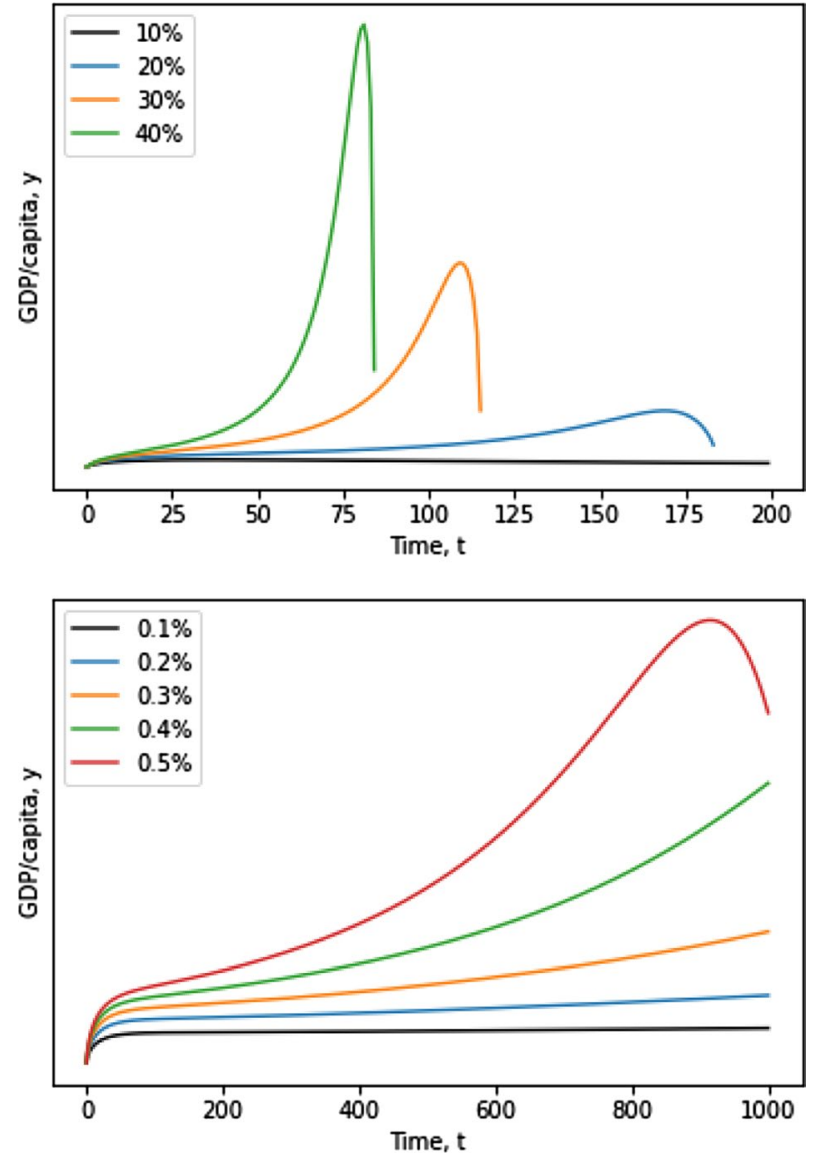

in the global aggregated perspectives provided by the Ecological Footprint approach from which the stark message that the world has already overshot derives (Wackernagel et al. 2019a, b). The trouble is that these measures are subject to measurement problems, practical rules of thumb and static assumptions, and remain open to question. In short they may not be sufficient evidence to convince the target audience. For instance, one of the reasons why the ecological footprint suggests that the world has overshot (there is an impact inequality) arises from excessive carbon emissions when gauged against the 1.5C target of the Paris Agreement. When converted into the required hectares of reforestation for this target our demands on the planet are pushed beyond global capacity (area). Taken literally, the implication seems to be that decarbonisation can only happen via land-based solutions. Technological change is also not always well captured by the measures. Furthermore, certain paradoxes raised about the lack of relationship between 'biocapacity' and GDP (see Wackernagel et al. (2019) for instance) are not convincing and neglect empirical evidence to the contrary (Brunnschweiler and Bulte 2008; van der Ploeg, 2010). However, on the other side, it can be argued that the ecological footprint underestimates the impact inequality, particularly in agriculture where the global hectares required are probably not a good measure of its overall impact on the biosphere. 
Many of these issues arise because of the scarcity of reliable data and the need for rough approximations to answer globally important questions. It is also an example of two literatures failing to talk to one another, ignoring the mutual gains of doing so to tighten up the arguments. Nevertheless, the fact that the Review has organised around the idea of embeddedness, and centred arguments for the impact inequality on contributions from the natural sciences will be influential in fixing ideas, guiding future research questions, and building the evidence base that can better illustrate the extent of the constraints. This will be the central point of debate with mainstream growth economists. So far, there are a few signs of engagement with these perspectives. ${ }^{8}$

\section{Addressing the Impact Inequality: Growth and Biodiversity Policy}

The remaining question is, given that the embedded economy is beyond the planetary boundary, what policies can be implemented to address the impact inequality? There are clearly demand side and supply side issues that can be addressed, and a range of policies that are required to address the absence of biodiversity values from everyday decisions.

\subsection{Policy Responses}

The review offers many of standard policies that are available in the environmental and resource economists toolkit, and some which are generally not. Microeconomic policy interventions include the use of corrective Pigouvian taxes or permit trading equivalents to reflect the shadow price of externalities, and the reduction of subsidies to harmful activities, such as agriculture and fossil fuels. Subsidies to biodiversity harmful sectors such as agriculture, fossil fuels and fisheries are in the order of US\$4-6 trillion annually, dwarfing the finance available for conservation. On macroeconomic policy the chief recommendation is to change the way that we measure economic performance, to focus less on GDP per capita and more on measures that reflect sustainability. This could include ensuring nonnegative genuine investment/saving measures or non-declining measures of comprehensive wealth in national accounts. Since their potential was first realised, these policies have not really broken through into day-to-day macro policy despite the clear connection to sustainable development and numerous examples of how this could be done (e.g.Arrow et al. 2012, in India and various chapters in Hamilton and Hepburn 2017). ${ }^{9}$ Hopefully the recommendations of the Review will be the push that is needed for policy makers to change tack. There are data issues, and real difficulties in estimating shadow/accounting prices as the Review recommends, but a number of indicators have been proposed that try to reflect sustainability in current measures of performance. The review points to Gross Ecosystem Product (China), the UN System of Environmental and Economic Accounts, and comprehensive wealth measures, even quantitative accounts, as fruitful ways forward. These approaches fit with the overall natural capital approach taken by the Review. Indeed, March 2021 saw the adoption by the UN of the System of Environmental Economic AccountingEcosystem Accounting (SEEA-EA), and the Gross Ecological Product (GEP) measure into

\footnotetext{
${ }^{8}$ e.g. See Martin Wolf's "Humanity is the cuckoo in the nest" in the Financial Times: https://www.ft.com/ content/a3285adf-6c5f-4ce4-b055-e85f39ff2988?.

9 The World Bank's WAVES program is another prominent example.
} 
the UN system of accounts (Ouyang et al. 2020). The former will complement GDP flow measures with measures of natural capital stocks, as recommended by the Review (and environmental economists since the $70 \mathrm{~s}) .{ }^{10}$

Yet in light of the previous section, these measures are necessary, but not sufficient. If we take the model and the evidence on NPP demands seriously, it is clear that a period of passive investment in the biosphere is required to restore natural capital and to reduce the impact inequality. Indeed, active investment in nature restoration is also required. Passive investment requires reducing $Y$ or increasing $\alpha_{Z}$ to obtain the materials balance. Passive investment: natural regrowth and restoration, will only happen when $\frac{d S}{d t}>0$. In the absence of quick technological fixes to limit the impact on the biosphere, this will require a drop in income: degrowth, followed by a move to a long run-steady state. Is degrowth politically feasible, particularly for low income countries? Probably not. Growth in India and China is in the order of $7 \%$ per annum at present, and there is no sign of this reversing any time soon, particularly where poverty reduction remains a priority. Technological change will clearly be important and whereas for climate change renewable energy is the key innovation, with regard to the biosphere, food systems and agriculture are likely to be the most important areas to relax the constraints of the biosphere and local ecosystems, and reduce the pressure on biodiversity. Restoration and quantitative restrictions (protected areas, rules on trade) will also be required to prevent further biodiversity losses. The Review recognises this (See Chapter 16 on Trade and the Biosphere).

Finally, with regard to closing the impact inequality, the stylised macro-policy decision is which steady state should be targeted? Chapter $11-13$ of the Review speaks to the relationship between wealth and natural capital accounting and the attainment of the optimal steady state. The guiding principle is that changes in wealth translate into changes in longrun well-being. Navigating the movement from an unsustainable impact inequality to a sustainable embedded economy can be best (with minimum cost to society) achieved by following these valuation principles, using appropriate accounting prices. Annex 13.1 shows some historical applications (Arrow et al. 2012), prefaced by the statement:

The publications should be viewed as reconnaissance exercises. You know they got it wrong, but you also know they are in the right territory.(p. 350)

There is much more work to be done in this area. The recent adoption inclusion of natural capital accounting in the UN-SEEA and GEP are useful and pragmatic steps in the right direction (see Ouyang et al. (2020) for an example of its application in China).

\subsection{Consumption, Fertility and Socially Embedded Preferences}

As Fig. 1 shows, population growth is also important. These two key issues: consumption levels in rich countries and population growth, deserve some attention, and the Review does not shy away from them. A key idea in the Review that is central to the proposed solutions in each case is that of socially embedded preferences. That is, what we do, how we act, is driven in part by social norms, habituation, traditions and reference dependencies, that are difficult to deviate from.

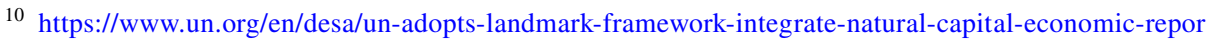
ting.
} 
The Review argues that preferences over consumption and fertility are socially embedded, meaning that much of our behaviour is governed by what our peers in society do. What we end up doing collectively derives from social norms, habits and other references that arise for reasons that are sometimes long since forgotten, or coordinate people in arbitrary ways. Dasgupta provides evidence to show that our consumption patterns and, indeed, fertility decisions (how many children women have) are to a large extent determined in this way. Bluntly, if people around you buy a new car every year, then it is highly likely that you will. If people in society have large families, it is more likely that you will too. It is difficult not to conform. We see evidence from around the world on how changing social norms may change consumption and fertility patterns. In a remarkable study, for instance, Jensen and Oster (2009) provide evidence on the role of cable TV in changing attitudes to fertility in India, while La Ferrara (2012) shows similar effects on fertility in Brazil as a result of popular telenovelas. Drawing upon a wealth of his own research, Dasgupta takes on the difficult topic of population growth and the environment through the lens of socially embedded preferences, and argues for and evidences the case that family planning has an important part to play in reducing the impact inequality, more so because of the externalities that embedded preferences give rise to.

Relating back to the question of income growth and its limitations, the issue of overconsumption is given a similar treatment. In each case the implication is that provided social norms can be augmented, and new, lower consumption and fertility equilibria can be arrived at without significant loss of welfare. Part of the idea is that if well-being is obtained via conformism, conforming to other norms would leave people no worse off and reduce demands on NPP. Looked at another way, both consumption decisions and fertility decisions within the household have significant external costs. This is a simplification of otherwise nuanced arguments presented in Chapter 13, which cover issues of human rights, gender, and how in the presence of externalities, clashes between rights arise, e.g. between fertility rights, and the rights of future generations. Can cable TV be relied upon to shift our conformist equilibria to one with lower resource intensity, be it on the consumption or, bluntly, the population side? Analysis of apparent public policy successes in this area suggest that public policy can invoke more than marginal changes. Theoretical results on multiple equilibria in social coordination problems are numerous, e.g. Nyborg (2020) in relation to smoking. While experimental evidence on multiple equilibria also exist in relation to issue of smoking and diet, it suggests that the mechanisms are complicated. Was the change in smoking behaviour in many European countries a shift from one conformist equilibrium to another, or just a standard response to higher costs due to bans in public places? Where nudges appear to work, there remains a question as to how permanent they are and also whether they are the preferred intervention. For instance, Vringer et al. (2017) show that in deciding whether household budgets should be allocated to more sustainable consumption bundles, people are reluctant to impose restrictions on others, preferring regulatory interventions. On consumption a key area is diet, and more work is needed to see how diets can be shifted (Willett et al. 2019), and how conformism can inhibit simple nudges and cause inertia. Indeed, this is an area in which changes in consumption could also solve a 'nutrition crisis' of excess, the economic costs of which run to almost US $\$ 2 \mathrm{Tr}$ per year for obesity related health care costs alone (Mande 2019, p. 14). ${ }^{11}$ There is certainly room for behavioural public policy here, but there remain questions as to scale and

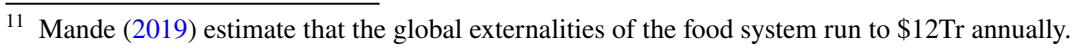


permanence, and precisely how individual motivations can be aligned with public policy goals (Banerjee and John, forthcoming, Garnett et al. 2019). Ultimately, not all consumption and fertility decisions are socially embedded.

\subsection{The Supply Side}

Rebalancing could be addressed on the supply side too, through passive investment (allowing ecosystems to regenerate naturally via, e.g. moratoriums on use) or by directly addressing restoration of habitats and ecosystems. This fits with the thrust of the UN Decade of Ecosystem Restoration (2021-2030) and is discussed at length in the Section 4.7, and Ch 19 of the Review, which describe successes in peatlands, wetlands, coral reefs. Ch 18 speaks to the conservation of nature and the role of protected areas and, more broadly, quantitative non-price measures. Indeed, a number of recent studies have attempted to show not just the economic gains of expanding protected areas, but also the financial gains (Waldron et al. 2020). ${ }^{12}$ The reason why such apparently low hanging fruit has not so far been picked is an interesting question, the answer to which lies in the property rights structures of natural resources and issues of local political economy. The potential costs of protected areas to local communities was one aspect of Waldron et al. (2020) that came in for criticism. ${ }^{13}$ The $30 \%$ target for protected areas is certainly a target that could coordinate activities and the CBD COP 15, but the localised and distributional impact should not be ignored given historical experiences.

While restoration and conservation activities serve an important supply side role, in aggregate and in the medium term technological change, and changes in consumption patterns, particularly diets, will ease passive investment. The review also explores the distributional implications of changes in consumption and remarks the burden of such changes ought not to fall on poor countries for whom rising incomes address poverty alleviation (See Ch 14 of the Review).

Thinking about distributional issues requires unpacking the stylized representative agent type model discussed above. Another issue in this regard is in the aggregated representation of the stock of primary producers and global flow of NPP. Of course, this stylization is purely illustrative, but the introduction of natural capital into the model means that Total Factor Productivity (TFP) as a multiplier of productive inputs could well be insufficient. ${ }^{14}$ With tightening natural capital options, we might be better served by separating out the efficiency with which elements of natural capital are used, asking whether the same output can be obtained with less natural inputs. To some extent this is recognized by discussion of the dependence of $\alpha_{Z}$ on $A$ (TFP), but perhaps factors that enter the model as a parameter directly on $S, R$, or possibly both depending on how we envision improvements in the efficient use of the environment in production are made, and how restoration and passive investment are achieved. There are X-inefficiency type issues, and perhaps issues concerning the use of natural inputs that might be labelled Total Factor Efficiency (TFE). Both highlight the role that innovation and investment in efficiency and clean production can make in stabilizing — even decreasing_our demands on the natural environment

\footnotetext{
12 The report is not peer reviewed at the time of writing: https://www.conservation.cam.ac.uk/files/waldr on_report_30_by_30_publish.pdf.

13 See e.g. https://www.resilience.org/stories/2021-01-12/an-open-letter-to-the-lead-authors-of-protecting30-of-the-planet-for-nature-costs-benefits-and-implications/

14 TFP is also a problematic concept in its own right (Fine 2016, ch5 ).
} 
wholly independent of other production processes. The details will be context specific, but improvements could be sought via, for instance, re-siting of productive processes: restricting production to fewer, more tightly regulated or less harmful sites.

Nevertheless, while such demand and supply side interventions interventions can change the flows of demand and the impacts on the biosphere, and are important parts of the response to the impact inequality, they do not change the fundamentals of physical planetary boundaries and the associated materials balance. The fundamental truth, the Review argues is that ultimately:

The efficiency with which its goods and services can be converted into produced goods and services is bounded. (p. 126)

\section{Biodiversity as Reflected in the Financial Sector}

Market failures with respect to nature and biodiversity are channelled through the financial sector, leading to the misallocation of capital and the facilitation of harmful activities. In Chapter 17 the review spends some time working through the failings of the sector to account for nature when allocating capital. The sector is also one of the target audiences for the Review. Throughout, the Review uses the language of assets and returns, makes the analogy of natural capital and ecosystem services as the return to nature. The idea of free passive investment: just leaving nature to regenerate and restore, as would happen in a moratorium on fisheries or forests for example, is used to make the issue at stake intuitive to a finance and macro/growth audience. Evidence is then provided to suggest that the returns to nature and biodiversity are an order of magnitude higher than the returns to physical capital and typical financial assets, hence there is under-investment in biodiversity and nature compared to other more traditional assets and capitals. This is not to say that demonstrating these returns will lead the financial sector to respond, more that there is work for policy and regulation to address the imbalance.

The special features of biodiversity that are explained in detail in the Review: (i) prone to tipping points and irreversible changes; and (ii) higher levels of biodiversity tending to reduce risks to many sectors including agricultural commodities, make biodiversity loss and the degradation of nature a concern for the financial sector. The physical risks associated with biodiversity loss have the potential to be material to many companies and investors. Box 17.1 in Ch 17 has some examples of the savings to insurance companies, for instance, provided by natural flood defenses (wetlands including mangroves). Barbier et al. (2018) estimate savings of up to \$52bn from global wetland conservation alone. Furthermore, with suitable policies, rules on trade (see chapter 18) and laws in place, there are also potentially transition risks and litigation risks. Stranded assets may also arise in nature just as for fossil fuels in relation to climate change. Agriculture and forestry may well be the industries that are vulnerable to being stranded. All of which may have implications for the value of sovereign debt for countries dependent on nature related industries and hence facing nature related risks. The downturns shown in Fig. 1 arising from the impact inequality and loss of biosphere natural capital, reflect in aggregate terms the kind of risks faced by an embedded economy. These risks affect economic activity, but the extent to which they are reflected in the financial sector at present is limited for biodiversity.

The potential connectedness of financial values to nature is well argued in Chapter 17. A great deal of work is required now to understand and price these risks in the financial sector as a whole. At present such values and risks are mispriced, capital is therefore 
misallocated, and damaging activities persist (Gostlow 2019). Indeed, a glut of other measures are required according to the Review to encourage companies and funds to understand the risks they face, measure the impacts their activities cause on biodiversity, and signal this information to investors and consumers. Disclosure mechanisms like the Taskforce for Nature Related Financial Disclosures (TNFD), categorisations like the EU Taxonomy approach (which categorises financial funds according to their impact on nature and sustainability), liability rules to call financial intermediaries to account for lending to damaging activities, and better information and pricing of nature related risks and nature linked bonds. ${ }^{15}$ These are some of the instruments available to embody biodiversity into investment decisions. ${ }^{16}$

The Review is descriptive and supportive of some of the measures and approaches being taken in the financial sector, in relation to green bonds and other macroeconomic initiatives related to nature and biodiversity. The Review is not particularly prescriptive however. Responses to the Dasgupta Review have laid out a clear agenda for the financial sector in relation to biodiversity. In an excellent summary of the entry points and remedies for nature in the finance sector, the response from Vivid Economics tells of the difficult task ahead. ${ }^{17}$ Here, it is argued inter alia that citizens should be empowered to make decisions that reflect their preferences over biodiversity and nature. This can be done in part by disclosure mechanisms that connect businesses and financial institutions to the impacts they have on biodiversity. Obviously rules are required to regulate particular behaviours. Liability mechanisms could be important here. Finally, biodiversity should be mainstreamed into the financial governance structure of financial institutions to ensure accountability for actions that cause damage, and promote stewardship. Regulations and mandates exist for disclosing other material risks, and these should be extended towards biodiversity related material risks and impacts. Perhaps current sources of information for material risks are insufficient. $^{18}$

There is much work to be done to establish the nature related risks that companies and funds face, as well as connecting the biodiversity related impacts to companies and funds. Understanding which financial mechanisms and instruments will be successful in this area is something that economists should now start establishing causal inference for. It is interesting to note the recent surge in companies and assets that fall under the Environment, Social and Governance (ESG) disclosure/ratings umbrella (an increase of 34\% since 2016), and the finding that such rated assets have weathered the COVID storm better (Albuquerque et al. 2020). Yet these findings, while promising, ought to be interpreted cautiously in terms of what is actually being achieved in each of the E, the $\mathrm{S}$ and the G. ${ }^{19}$ For instance, Berg et al. (2020) show the inconsistencies that exist between different ESG ratings agencies, which sometimes come to different conclusions about the same companies,

\footnotetext{
15 https://www.bloomberg.com/news/articles/2021-02-25/first-sovereign-nature-bonds-get-lift-from-worldbank-backed-hub?sref=HkIFZ0t4.

16 On April 1st 2021, 9 members of the EU Taxonomy advisory group resigned due to the apparent watering down of the EU taxonomy definitions of which industries can be classified as sustainable. https://www. reuters.com/article/europe-regulations-finance-idUSL4N2LT4LJ.

17 see https://www.f4b-initiative.net/publications-1/the-dasgupta-review\%3A-what-it-means-for-the-globalfinancial-system.

18 Gostlow (2020) points out that Form 8k may provide more pertinent sources of information about susceptibility to climate risk that the usual $10 \mathrm{k}$.

19 Establishing causality is also a major empirical issue.
} 
and which are more generally uncorrelated with one another across attributes. ${ }^{20}$ Compare this to risk ratings, which are highly correlated across raters, and contain much of the same information.

There is also concern about ESG being an exercise in greenwash, given the difficulty in separating out the different components, and tying ratings to specific actions on the ground. One also may have to take the rough with the smooth, as it were. British Allied Tobacco is in the top 3 ESG rated firms of the FTSE100 due to, it is reported, its net-zero pledges, commitment to reduced water use and more sustainable agriculture (E) and treatment of workers $(G)$. It is obviously performs less well in other other dimensions $(S){ }^{21}$ Also in the top 3, AstraZeneca scores highly due a commitment to sell vaccines at cost, while Glaxo Smith Klein have various net-zero carbon and nature neutral commitments by 2030. Such companies may not suit all investors that are interested in sustainability, climate change and nature.

Such is the concern about greenwash that the European Union has recently imposed higher levels of regulation on ESG ratings, the Sustainable Finance Disclosure Regulations (SFDR) to ensure that ESG rated funds publish their sustainability processes, and have generally more rigorous disclosures that assist investors in making decisions. Yet, remarkably, lobbying removed deforestation from the list of issues that should be reported on. ${ }^{22}$ These are some of the potentially confusing outcomes that Berg et al. (2020) have pointed out. The Review also lauds other disclosure type mechanisms such as the TNFD. The TNFD is being constructed in the mould of a similar mechanism for climate disclosures. The success of such disclosure mechanisms, think also of the Transition Pathway Initiative (TPI), is often measured in terms of the asset values of the firms that sign up to disclose, rather than what is disclosed per se. The TPI reports sector by sector on carbon emissions against sector level benchmarks for performance, and how these relate to the target of the Paris Agreement to limit temperatures to below $2 \mathrm{C}^{23}$. So the TPI is somewhat clear about its benchmarks. Yet among the US\$23Tr of assets that have signed up to the TPI, only 14\% are aligned to the $2 \mathrm{C}$ target of the Paris Agreement. While more are aligned with the country level Nationally Determined Contribution (NDCs) typically NDCs are insufficient to meet the target. ${ }^{24}$ On the other hand, around $60 \%$ of firms have processes in place to manage their own material climate risks. So there is a long way to go to connect ESG ratings which affect the demand side, with action on the ground on the supply side of biodiveristy benefits. The Review provides a good overview of the work that is being undertaken in the sector. Overall though, some care is needed to ensure that conformity to one set of standards, e.g. ESG, TNFD, does not perversely provide even more space for those companies and investors who do not conform.

\footnotetext{
20 The Aggregate Confusion Project: https://mitsloan.mit.edu/sustainability-initiative/aggregate-confusionproject.

21 https://www.hl.co.uk/news/articles/ftse-100-the-5-highest-esg-rated-companies.

22 https://www.ft.com/content/74888921-368d-42e1-91cd-c3c8ce64a05e.

23 see https://www.transitionpathwayinitiative.org/publications/77.pdf?type=Publication and the TPI tool.

24 https://www.transitionpathwayinitiative.org/publications/74.pdf?type=Publication.
} 


\section{Conclusion}

The Review is more than its focus on limits to growth and how to reverse the impact inequality. It rehearses all the economic aspects of biodiversity loss, recognises the role of institutions and property rights, the failure of markets, and the difficulties of bringing future generations, an important constituency in relation to biodiversity, to the table when making social choices. These are well known arguments in economics, and they are well articulated here in the context of nature and biodiversity.

The idea of limits to growth is controversial, and it will be debated further. It is difficult to envisage the future crashes predicted even by optimal growth paths in an embedded economy (See Figs. 1, 2 and 3). The prescriptions of the Review, which revolve around pricing biodiversity properly so that it affects our day to day decisions, the decisions of companies and investors and the programmes and policies that governments implement, are less controversial to economists. Yet, the fact that these prescriptions rely in great measure on valuation of biodiversity may sit uneasily with those who see biodiversity as more than the instrumental values that such valuations might imply. Some may find the very language of assets, prices and natural capital irksome for this reason. The use of the term capital conjures up an association with capitalism, and the sense that economists are the problem, rather than the solution here. The hackneyed phrase that an economist knows the price of everything and the value of nothing, may well make a comeback in the aftermath of the Review. ${ }^{25}$

The opposite is closer to the objective for environmental and ecological economists. A major part of the process of valuation is to point out the low value that decisions makers (consumers, financiers, governments, international agencies) place on biodiversity and the environment in their day to day decisions. Neither is the Review so narrow in its discussion of values in its opening chapters, explaining a plurality of views. Of course there are problems that economists need to recognise with commodification and invaluable goods in general, and how valuation of such goods (e.g. rights, principles, perhaps biodiversity), may change us or our individual relationship with them (Pascual et al. 2021). Partly in light of some of these issues, the Review recognises the need for both quantitative as well as pricing measures. There are places that humans simply ought not to go for reasons of intrinsic value, as much as for instrumental reasons of, for instance, reducing contact with zoonoses. Yet, at the same time in a paper entitled 'Invaluable Goods' Ken Arrow makes the point that:

politicising activities is no greater guarantee of preserving individuation as commodifying them. (Arrow 1997)

In short, rather than one or the other, balance is required between valuation and participation. Associating natural capital, valuation and shadow prices with capitalism potentially misses the point. ${ }^{26}$ Firstly, that markets, including financial markets, are failing biodiversity is central to the Review. Shadow or accounting prices are required to correct the misallocations that this leads to, both spatially and intertemporally, in their neglect of future generations. Of course, the theory of change which works through 'correcting externalities'

\footnotetext{
25 The original quote refers to a cynic. Interestingly the less heard part of the dialogue continues: "And a sentimentalist, my dear Darlington, is a man who sees an absurd value in everything and doesn't know the market price of any single thing.

26 Statements like this can be found in the IPBES Draft Values Assessment for instance.
} 
or 'correcting markets' may not appeal to everyone, but shadow pricing and valuation in general is not best characterised as a capitalist endeavour. Leonid Kantorovich and Tjalling Koopmans won the Nobel Prize in 1975 for their work on allocation and planning in the macroeconomy. The former worked on planning within the Soviet Union, the latter in the US, back when the question of whether market or planned economies were better at solving allocation problems was at its height. Both found the use of shadow pricing central to solving allocations problems and making tradeoffs between different aspects of the plan. So the concept of a shadow price is not necessarily associated with market, capitalist economies. Shadow prices reflect the societal objectives, be they utilitarian, or focused on sustainability or fairness more generally (Turk et al. 2020). Both approaches fail if the impact of the economy on the environment is neglected from the plan, even more so if the economy is as Dasgupta sees it: embedded in the environment. Understanding the constraints, defining the societal objectives, measuring performance properly, reflecting these in day to day decisions, this is the change in the economic grammar that the Review calls for.

Finally, the comparison of the Dasgupta Review with the Stern Review is irresistible. The UK now has the climate act and a net zero target for 2050, with interim targets to stop slippage. The Nordhaus-Stern-Weitzman debate in the aftermath of the Stern Review raised the profile of the Stern Review tremendously, and raised the profile of climate economics in the profession. In the Paris Agreement we have some political consensus. The hope for the Dasgupta Review on the economics of biodiversity must be the same: that it will become the go to source of information for policy makers, speak to the institutions that can effect aggregate change: finance ministries, central banks and large corporations and international organisations, in the run up to the COP15 of the Convention on Biodiversity Economics, and serve as the impetus for action. Rather than distracting discussions about the discount rate, however, the core controversy among economists will probably surround the new grammar proposed for the economics of growth, encapsulated by embeddedness and limits to growth. The evidence here looks beyond doubt when one focuses on headline figures for biodiversity loss, such as Bradshaw et al. (2021), but many will not put their faith in ecological footprints as the key measure upon which catastrophic predictions should turn. Furthermore, the arrow of causality between economists and policy change is a difficult one to evaluate (e.g. Groom and Hepburn 2017), and the theory of change in the Review weights heavily the correction of markets, when clearly other structural, institutional and political changes will be required. Not least among these will be a binding agreement at the COP15 which, unlike the Paris Agreement, has real teeth. Yet, while we await Dasgupta's colleagues in the economics profession to be persuaded, biodiversity should not be assigned a value of zero at the point of decision. Measuring natural capital, reorientating the financial sector, placing limits where necessary, rethinking our social norms, and yes getting shadow prices right, will all help to safeguard biodiversity and future generations, as well as current generations. In the past year we have already witnessed the sharp changes in policy that are possible when faced with catastrophic events. Similar step changes are likely to be required in relation to Biodiversity. Overall, the Review makes this case.

Open Access This article is licensed under a Creative Commons Attribution 4.0 International License, which permits use, sharing, adaptation, distribution and reproduction in any medium or format, as long as you give appropriate credit to the original author(s) and the source, provide a link to the Creative Commons licence, and indicate if changes were made. The images or other third party material in this article are included in the article's Creative Commons licence, unless indicated otherwise in a credit line to the material. If material is not included in the article's Creative Commons licence and your intended use is not 
permitted by statutory regulation or exceeds the permitted use, you will need to obtain permission directly from the copyright holder. To view a copy of this licence, visit http://creativecommons.org/licenses/by/4.0/.

\section{References}

Acemoglu D, Philippe A, Leonardo B, Hemous D (2012) The environment and directed technical change. Am Econ Rev 102(1):131-166

Acemoglu D, Aghion P, Bursztyn L, Hemous D, Johnson S, Robinson JA (2001) The colonial origins of comparative development: an empirical investigation. Am Econ Rev 91(5):1369-1401

Aghion P, Alesina A, Trebbi F (2004) Endogenous political institutions. Q J Econ 119(2):565-611

Albuquerque R, Koskinen Y, Yang S, Zhang C (2020) Resiliency of environmental and social stocks: an analysis of the exogenous COVID-19 market crash. Rev Corp Finance Stud 9(3):593-621

Arrow KJ (1997) Invaluable goods. J Econ Lit 35(2):757-765

Arrow KJ, Dasgupta P, Goulder LH, Mumford KJ, Oleson K (2012) Sustainability and the measurement of wealth. Environ Dev Econ 17(3):317-353

Arrow K, Dasgupta P, Goulder L, Daily G, Ehrlich P, Heal G, Levin S, Maler K-G, Schneider S, Starrett D, Walker B (2004) Are we consuming too much? J Econ Perspect 18(3):147-172

Banerjee S, John P(forthcoming) Nudge plus: incorporating reflection into behavioral public policy. Behav Public Policy 1-16

Bar-On YM, Phillips R, Milo R (2018) The biomass distribution on Earth. Proc Natl Acad Sci 115(25):6506-6511

Barbier EB, Burgess JC, Dean TJ (2018) How to pay for saving biodiversity. Science 360(6388):486-488

Berg F, Koelbel J, Rigobon R (2020) Aggregate confusion: the divergence of ESG ratings. SSRN

Boulding KE (1968) Beyond economics: essays on society, religion, and ethics

Bradshaw CJA, Ehrlich PR, Beattie A, Ceballos G, Crist E, Diamond J, Dirzo R, Ehrlich AH, Harte J, Harte ME, Pyke G, Raven PH, Ripple WJ, Saltre F, Turnbull C, Wackernagel M, Blumstein DT (2021) Underestimating the challenges of avoiding a ghastly future. Front Conserv Sci 1:9

Brander JA, Taylor MS (1998) The simple economics of Easter Island: a Ricardo-Malthus model of renewable resource use. Am Econ Rev 88(1):119-138

Brock WA, Xepapadeas A (2003) Valuing biodiversity from an economic perspective: a unified economic, ecological, and genetic approach. Am Econ Rev 93(5):1597-1614

Brunnschweiler CN, Bulte EH (2008) The resource curse revisited and revised: a tale of paradoxes and red herrings. J Environ Econ Manag 55(3):248-264

Ceballos G, Ehrlich PR, Barnosky AD, García A, Pringle RM, Palmer TM (2015) Accelerated modern human-induced species losses: Entering the sixth mass extinction. Sci Adv 1(5):e1400253

Copeland BR, Taylor MS (2004) Trade, growth, and the environment. J Econ Lit 42(1):7-71

Courtois P, Figuieres C, Mulier C (2014) Conservation priorities when species interact: the Noah's Ark metaphor revisited. PLoS One 9(9):e106073-e106073

Daily GC, Ehrlich PR (1996) Global change and human susceptibility to disease. Annu Rev Energy Environ 21(1):125-144

Dasgupta PS, Heal GM (1980) Economic theory and exhaustible resources. Cambridge University Press, Cambridge

Dasgupta P (2010) Nature's role in sustaining economic development. Philos Trans Biol Sci 365(1537):5-11

Dasgupta P, Heal G (1974) The optimal depletion of exhaustible resources. Rev Econ Stud 41:3-28

La Ferrara E, Chong A, Duryea S (2012) Soap operas and fertility: evidence from Brazil. Am Econ J Appl Econ 4(4):1-31

Fine B (2016) Microeconomics: a critical companion. Pluto Press, Febrero

Fleurbaey M (2013)Beyond GDP measuring welfare and assessing sustainability

Garnett EE, Balmford A, Sandbrook C, Pilling MA, Marteau TM (2019) Impact of increasing vegetarian availability on meal selection and sales in cafeterias. Proc Natl Acad Sci 116(42):20923-20929

Georgescu-Roegen N (1971) The entropy law and the economic process. Harvard University Press, Cambridge

Gostlow G (2019) Pricing climate risk

Gostlow G (2020) The materiality and measurement of physical climate risk: evidence from form 8-K

Groom B, Hepburn C (2017) Reflections-looking back at social discounting policy: the influence of papers, presentations, political preconditions, and personalities. Rev Environ Econ Policy 11(2):336-356 
Hamilton K, Hepburn C (2017) National wealth: what is missing, why it matters. Oxford University Press, Oxford

Hamilton K, Hepburn C, Hartwick J (2014) Wealth and sustainability. Oxford Rev Econ Policy 30(1):170-187

Hamilton K, Hepburn C, Hartwick J, Clemens M (1999) Genuine savings rates in developing countries. World Bank Econ Rev 13(2):333-356

Hartwick JM (1977) Intergenerational equity and the investing of rents from exhaustible resources. Am Econ Rev 67(5):972-974

Jean-Louis F, Caroline A, Louis O (1998) An overview of the Weitzman approach to diversity. Genet Sel Evol 30(2):149-161

Jensen R, Oster E (2009) The power of TV: cable television and women's status in India. Q J Econ 124(3):1057-1094

Jones CI, Klenow PJ (2016) Beyond GDP? Welfare across countries and time. Am Econ Rev 106(9):2426-2457

Mace GM (2014) Biodiversity: its meanings, roles, and status. In: Nature in the balance. Oxford University Press, Oxford

Mande J et al (2019) Report of the 50th anniversary of the White House conference on food, nutrition, and health: honoring the past, taking actions for our future. Boston, MA

Neumayer E (2012)Human development and sustainability

Nordhaus WD (2017) Revisiting the social cost of carbon. Proc Natl Acad Sci 114(7):1518-1523

Nyborg K (2020) No man is an island: social coordination and the environment. Environ Resour Econ 76(1):177-193

Ouyang Z, Song C, Zheng H, Polasky S, Xiao Y, Bateman IJ, Liu J, Ruckelshaus M, Shi F, Xiao Y, Xu W, Zou Z, Daily GC (2020) Using gross ecosystem product (GEP) to value nature in decision making. Proc Natl Acad Sci 117(25):14593-14601

Pascual U, Adams WM, Diaz S et al. (2021) Biodiversity and the challenge of pluralism. Nature Sustain

Pepin J (2013) The origins of AIDS: from patient zero to ground zero. J Epidemiol Commun Health 67(6):473-475

Pezzey JCV (2004) One-sided sustainability tests with amenities, and changes in technology, trade and population. J Environ Econ Manag 48(1):613-631

Reist-Marti SB, Simianer H, Gibson J, Hanotte O, Rege JEO (2003) Weitzman's approach and conservation of breed diversity: an application to African cattle breeds. Conserv Biol 17(5):1299-1311

Rockstrom J, Steffen W, Noone K, Persson A, Stuart CF III, Lambin EF, Lenton TM, Scheffer M, Folke C, Schellnhuber HJ, Nykvist B, de Wit CA, Hughes T, van der Leeuw S, Rodhe H, Sorlin S, Snyder PK, Costanza R, Svedin U, Falkenmark M, Karlberg L, Corell RW, Fabry VJ, Hansen J, Walker B, Liverman D, Richardson K, Crutzen P, Foley JA (2009) A safe operating space for humanity: identifying and quantifying planetary boundaries that must not be transgressed could help prevent human activities from causing unacceptable environmental change, argue Johan Rockstrom and colleagues. Nature 461(7263):472

Romer PM (1990) Endogenous technological change. J Political Econ 98(5):S71-S102

Samuel AF, Drucker AG, Andersen SB, Simianer H, van Zonneveld M (2013) Development of a cost-effective diversity-maximising decision-support tool for in situ crop genetic resources conservation: the case of cacao. Ecol Econ 96:155-164

Simianer H, Simianer H (2008) Accounting for non-independence of extinction probabilities in the derivation of conservation priorities based on Weitzman's diversity concept. Conserv Genetics 9(1):171-179

Solow RM (1994) Perspectives on growth theory. J Econ Perspect 8(1):45-54

Steffen W, Richardson K, Rockstrom J, Cornell SE, Fetzer I, Bennett E, Biggs R, de Vries W (2015) Planetary boundaries: guiding human development on a changing planet. Science 347(6223):1259855

Stiglitz J (1974) Growth with exhaustible natural resources: efficient and optimal growth paths. Rev Econ Stud 41:123-137

Turk Z, Groom B, Fenichel E (2020) Mean-spirited growth. Grantham Research Institute on Climate Change and the Environment working paper 351

van den Bergh JCJM (2011) Environment versus growth-a criticism of "degrowth" and a plea for "agrowth ". Ecol Econ 70(5):881-890

van der Heide CM, van den Bergh JCJM, van Ierland EC (2005) Extending Weitzman's economic ranking of biodiversity protection: combining ecological and genetic considerations. Ecol Econ 55(2):218-223

van der Ploeg F, Poelhekke S (2010) The pungent smell of "red herrings": subsoil assets, rents, volatility and the resource curse. J Environ Econ Manag 60(1):44-55

Vringer K, Van Der Heijden E, Van Soest D, Vollebergh H, Dietz F (2017) Sustainable consumption dilemmas. Sustainability 9(6):942 
Wackernagel M, Beyers B, Rout K (2019a) Ecological footprint: managing our biocapacity budget. New Society Publishers, Gabriola Island

Wackernagel M, Lin D, Evans M, Hanscom L, Raven P (2019b) Defying the footprint oracle: implications of country resource trends. Sustainability 11(7):2164

Waldron A et al (2020) Protecting 30\% of the planet for nature: costs, benefits and economic implications. unpublished manuscript. https://www.conservation.cam.ac.uk/files/waldron_report_30_by_30_publi sh.pdf

Weitzman ML (2009) On modeling and interpreting the economics of catastrophic climate change. Rev Econ Stat 91(1):1-19

Walter W, Rockstrom J, Loken B, Springmann M, Lang T, Vermeulen S, Garnett T, Tilman D, DeClerck F, Wood A, Jonell M, Clark M, Gordon LJ, Fanzo J, Hawkes C, Zurayk R, Rivera JA, De Vries W, Sibanda LM, Afshin A, Chaudhary A, Herrero M, Agustina R, Branca F, Lartey A, Fan S, Crona B, Fox E, Bignet V, Troell M, Lindahl T, Singh T, Cornell SE, Reddy KS, Narain S, Nishtar S, Murray CJL (2019) Food in the Anthropocene: the EAT-Lancet Commission on healthy diets from sustainable food systems. Lancet 393(10170):447-492

Wu F, Zhao S, Bin Y, Chen Y-M, Wang W, Song Z-G, Yi H, Tao Z-W, Tian J-H, Pei Y-Y, Yuan M-L, Zhang Y-L, Dai F-H, Liu Y, Wang Q-M, Zheng J-J, Lin X, Holmes EC, Zhang Y-Z (2020) A new coronavirus associated with human respiratory disease in China. Nature 579(7798):265-269

Publisher's Note Springer Nature remains neutral with regard to jurisdictional claims in published maps and institutional affiliations. 